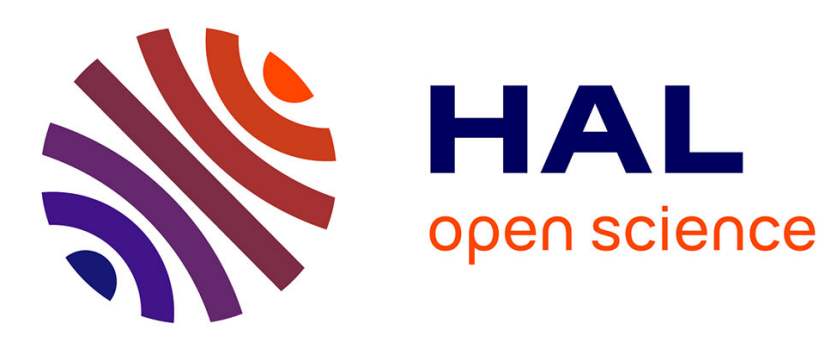

\title{
Renewable resource management, user heterogeneity, and the scope for cooperation
}

K. Erdlenbruch, M. Tidball, D. van Soest

\section{To cite this version:}

K. Erdlenbruch, M. Tidball, D. van Soest. Renewable resource management, user heterogeneity, and the scope for cooperation. Ecological Economics, 2008, 64 (3), p. 597 - p. 602. 10.1016/j.ecolecon.2007.04.004 . hal-00453888

\section{HAL Id: hal-00453888 \\ https://hal.science/hal-00453888}

Submitted on 5 Feb 2010

HAL is a multi-disciplinary open access archive for the deposit and dissemination of scientific research documents, whether they are published or not. The documents may come from teaching and research institutions in France or abroad, or from public or private research centers.
L'archive ouverte pluridisciplinaire HAL, est destinée au dépôt et à la diffusion de documents scientifiques de niveau recherche, publiés ou non, émanant des établissements d'enseignement et de recherche français ou étrangers, des laboratoires publics ou privés. 


\title{
Renewable resource management, user heterogeneity, and the scope for cooperation*
}

\author{
Katrin Erdlenbruch ${ }^{1}$, Mabel Tidball ${ }^{2 \dagger}$, and Daan van Soest ${ }^{3}$ \\ ${ }^{1}$ Cemagref, UMR LAMETA and G-EAU, Montpellier, France \\ ${ }^{2}$ INRA, UMR LAMETA, Montpellier, France \\ ${ }^{3}$ Tilburg University, Department of Economics and CentER, Tilburg, The Netherlands
}

\begin{abstract}
Cooperation can increase the efficiency of commonly-owned renewable resource use. However, received knowledge is that, absent side payments, cooperative solutions are more difficult to achieve the less homogenous the agents involved. We revisit this claim by analyzing how differences in the opportunity costs of resource harvesting affect the scope for Pareto-improving contracts, where contracting is with respect to the type of technology used. We find that the scope for cooperation is largest for intermediate levels of heterogeneity.
\end{abstract}

JEL classification: C73, Q20.

Key words: shared resource use, dynamic game, heterogeneous agents, contracts.

\section{Introduction}

Absent cooperation, rates of extraction are suboptimally high if a renewable natural resource is shared by two users, or more. Achieving cooperation is typically thought to be more difficult if resource users are heterogeneous, for example with respect to the efficiency with which they can exploit the resource (cf. Cherry et al. 2005, Gardner et al. 2000, Hannesson 1997, Johnson and Libecap 1982, Ledyard 1995, Munro 1979, Varughese and Ostrom 2001).

One reason why heterogeneity renders cooperation less likely is that it is not immediately clear what a fair allocation of the 'gains from cooperation' entails. Heterogeneity implies that the direct gains from cooperation are asymmetric and this complicates achieving Pareto improving solutions, especially if side payments are not feasible. As noted by

\footnotetext{
*The authors gratefully acknowledge the European Union's financial support via the Fifth European Framework's BIOECON project, and Daan van Soest also thanks the Netherlands Organisation for Scientific Research for their support as part of the program on 'Evolution and Behavior'. Furthermore, we thank Trond Bjørndal, Timothy Swanson, Franz Wirl and two anonymous referees for useful comments on an earlier version of this paper. The usual disclaimer applies.

${ }^{\dagger}$ Corresponding author: Mabel Tidball, LAMETA-INRA, 2 place P.Viala, 34060 Montpellier Cedex 1, France. Tel: +33 499612 245, tidball@supagro.inra.fr.
} 
Johnson and Libecap (1982), heterogeneity may therefore lead to (possibly prohibitively) high contracting costs. And side payments are often infeasible in practice because of practical or political constraints (Munro 1979). A second reason regards information and monitoring costs. The more dissimilar agents are with respect to skills or preferences, the more difficult it is for each individual user to infer whether their peers effectively adhere to the agreement, or not.

We contribute to the literature on the relationship between user heterogeneity and the scope for cooperation by focusing on the role of the choice of harvesting technologies herein. Technology choice is potentially able to alleviate (or even solve) both problems cited above - the monitoring problem as well as the problem of those who gain from cooperation not being able to directly compensate those who lose. Clearly, while extraction is often difficult to monitor, the type of harvesting technology used is relatively easy to observe. And because each agent can infer the other agents' privately optimal extraction given their harvesting technologies, contracting with respect to the technology type solves the monitoring problem regarding extraction itself. Second, as different technologies generate different returns to harvesting effort, technology choice can be an -albeit imperfectsubstitute for side payments.

To analyze to what extent technology choice can foster cooperation and how it interacts with the degree of heterogeneity among the various resource users, we construct a twocountry dynamic game (in spirit of Benhabib and Radner 1988, Clark 1980, Levhari and Mirman 1980). In each country there are two industries, agriculture and a resource sector. Harvesting productivity in the resource sector depends not only on the type of technology used, but also on the size of the resource stock: the larger it is, the lower the costs of harvesting an additional unit. The two countries share access to the resource, and differ only with respect to agricultural productivity - that is with respect to the instantaneous opportunity costs of resource harvesting. ${ }^{1}$ Absent cooperation, the dynamic game results in overexploitation of the resource, with both countries selecting the best available technology and allocating too much labor to resource harvesting. The two countries involved can potentially increase aggregate payoffs by selecting a less-than-

\footnotetext{
${ }^{1}$ Obviously, this is just one possible source of heterogeneity. For the consequences of other sources such as differences in discount rates, see for example Munro (1979), Houba et al. (2000) and Crabbé and Van Long (1993).
} 
perfect technology, thus accepting a decrease in technical harvesting productivity in order to increase productivity associated with having larger resource stocks.

We analyze the relationship between user heterogeneity and the scope for signing mutually beneficial technology contracts by determining the range of Pareto-improving technology sets as a function of the difference in agricultural productivity. ${ }^{2}$ We find that this range is largest at intermediate levels of heterogeneity, and hence the relationship between heterogeneity and the scope for cooperation is humpshaped. The reason is that for low levels of heterogeneity there is little opportunity for specialization whereas for high levels of heterogeneity, there is less need for cooperation. ${ }^{3}$

The setup of the paper is as follows. We describe the model in section 2. In section 3 , we present the solutions of the non-cooperative game and of the socially optimal program, analyze the design of Pareto-improving contracts and explore the role of heterogeneity therein. Finally, section 4 concludes. All proofs are available upon request.

\section{The model}

We consider two countries, referred to with subscripts $\{i, j\}=\{1,2\}$. These countries have shared access to the same renewable resource (with size $R(t)$ at time $t$ ), and are also able to undertake agriculture. Prices for the agricultural and resource commodities produced (denoted by $P_{a}$ and $P_{r}$ ) are determined in international markets, and are constant over time. Each country aims to maximize the net present value of the profit flow of agriculture and resource harvesting. It does so (i) by choosing a harvesting technology $\beta_{i}$ from a range of available technologies $(0, \bar{\beta}]$, and (ii) by deciding how much labor to allocate to resource harvesting $l_{r i}(t)$, taking into account the other country's decisions. Regarding the costs of adopting a harvesting technology, we impose the simplifying assumptions that

\footnotetext{
${ }^{2}$ By focusing on the range of Pareto-improving contracts, we do not address the question which contract will actually be selected. Hence, we ignore bargaining problems (see for example Houba et al. 2000).

${ }^{3}$ The only paper we are aware of that also finds that heterogeneity does not necessarily complicate obtaining efficient outcomes is that of Gaspart and Seki (2003). They consider the case where agents differ with respect to production skills, and where each agent's social status is an increasing function of his/her relative output performance. Best response implies that social status considerations tend to induce agents to mitigate differences in output performance by adjusting effort. Therefore, non-cooperative behavior may actually result in efficient production levels -but only if skill heterogeneity is not too large. Gaspart and Seki thus find that there is less need for cooperation if agents are sensitive to relative status. In contrast, in our paper the non-cooperative solution is only efficient in the trivial case where just one agent harvests (and the other prefers not to).
} 
all technologies are equally expensive $\left(I_{\beta}=I>0\right.$ for all $\left.\beta \in(0, \bar{\beta}]\right)$ and that they can be discarded at zero cost. Hence, country $i$ 's maximization problem is:

$$
\Pi_{i}=\max _{l_{r i}, \beta_{i}}\left[-I \phi_{i}+\int_{0}^{\infty}\left(P_{a} q_{a i}(t)+P_{r} q_{r i}(t)\right) e^{-\delta t} d t\right]
$$

subject to

$$
\begin{gathered}
q_{a i}(t)=\alpha_{i} l_{a i}(t), \quad q_{r i}(t)=\beta_{i} \phi_{i} R l_{r i}(t), \quad \bar{l}=l_{a i}(t)+l_{r i}(t) \\
\dot{R}(t)=\rho R(t)(K-R(t))-q_{r i}(t)-q_{r j}(t), \quad R(0)=R_{0}>>0 .
\end{gathered}
$$

In objective function (1), $\phi_{i}$ is an indicator function which takes on value 1 if country $i$ decides to adopt a harvesting technology from the range $(0, \bar{\beta}]$, and 0 otherwise. Furthermore, $q_{a i}(t)$ and $q_{r i}(t)$ are the quantities produced in period $t$ by country $i$, and $\delta$ is the discount rate. In (2), agricultural output is a linear function of labor input $l_{a i}(t)$ with constant marginal productivity $\alpha_{i}$. The harvest function $q_{r i}(t)$ is the standard Schaefer production function. Its arguments are labor input $l_{r i}(t)$ and the resource stock $R(t) .{ }^{4}$ Furthermore, $\beta_{i}$ is the so-called catchability coefficient of the harvesting function, and reflects the share of the fish stock $(q / R)$ that is harvested per unit of effort employed per period $l_{r}{ }^{5}$ If $\phi_{i}=1, \beta_{i}>0$ the country is - in principle - able to generate harvesting revenues. ${ }^{6}$ Therefore, decisions regarding $\beta_{i}$ embody the choice of the harvesting technology used, and given that it reflects the share harvested, this parameter must be bounded from above (i.e, $\left.\beta_{i} \in(0, \bar{\beta}]\right)$. Note that the Schaefer specification implies that labor's physical marginal product in harvesting is determined by two factors: the type of

\footnotetext{
${ }^{4}$ Note that the Schaefer harvesting function is special as it assumes increasing returns to scale. If both inputs $\left(l_{r}\right.$ and $R$ ) are doubled, the amount of resource harvested is quadrupled. Indeed, this is a key characteristic of the Schaefer specification, and well-noted in the fisheries literature. The main reason why it is often used is its mathematical convenience, but it can be defended on the basis that it captures search costs. Take the example of a fishery where fish tend to spread evenly over the available waters. Then, the larger the size of the stock, the higher the fish density and the more fish will be caught per sweep of the net.

${ }^{5}$ The parameter can be interpreted in several ways. For example, in the case of a fishery it may reflect the type of fishing gear used (fishing rods, or nets), the mesh size of the nets used, the number of nets used simultaneously, the size of the boat used, the average speed of the boat used, etc. Some of these inputs can be viewed as capital that can be accumulated over time, others not. Specifically including capital would result in a model with two state variables, which are very difficult to solve. We follow the bulk of the renewable resource literature and think of $\beta$ as a harvesting technology (a boat, or a net) that can be chosen freely and which comes in different sizes with different levels of productivity.

${ }^{6}$ Clearly, the assumption that all technologies are equally expensive $\left(I_{\beta}=I \forall \beta \in(0, \bar{\beta}]\right)$ is less offending in case $\beta$ reflects mesh size (i.e., nets with finer mesh size are not likely to be much more expensive than nets with larger mesh size) than if it is thought to reflect boat size or speed; cf. footnote 5. Note, however, that our results are even reinforced if we were to assume investment costs to be an increasing function of technological productivity.
} 
technology chosen $(\beta)$, and the size of the resource stock $(R)$. The last equation in $(2)$ is the labor time constraint, with $\bar{l}$ the labor endowment per period and $l_{a i}(t)$ the amount of labor allocated to agriculture.

The dynamics of the resource stock are given by (3), with $\rho$ the intrinsic growth rate and $K$ the carrying capacity. Because of their joint impact on the size of the resource stock, the two countries are tied in a game, where the initial resource stock equals $R_{0}$. The two countries only differ with respect to agricultural productivity, $\alpha_{i}$, which is an inherent characteristic of the country's location (climate, soils, etc.).

The last three assumptions are the following. First, country 1 is assumed to have a natural advantage with respect to agricultural production relative to country $2 ; \alpha_{1}>\alpha_{2}$. Second, each country is able to drive the resource stock to extinction if it adopts the

most efficient harvesting technology $\bar{\beta}$, and a sufficient condition for this to hold is that $\bar{\beta} \bar{l}>\rho K$. Third, the costs of purchasing a harvesting technology $(I)$ are sufficiently low and the initial resource stock $\left(R_{0}\right)$ is sufficiently large such that harvesting is a profitable enterprise for both countries involved. Hence, $\phi_{i}=1$ for $i=\{1,2\}$.

\section{Pareto-improving contracts}

Our model is very similar to that of Clark (1980), from which we can derive the noncooperative solution.

Proposition 1 The Nash equilibrium feedback solution is that both countries adopt the best harvesting technology $(\bar{\beta})$, and the allocation of harvesting effort is as follows:

$$
\begin{gathered}
l_{r 1}^{N *}(t)=\left\{\begin{array}{lll}
\bar{l} & \text { if } \quad R(t)>\bar{R}_{1} \\
0 & \text { if } R(t) \leq \bar{R}_{1}
\end{array}\right. \\
l_{r 2}^{N *}(t)=\left\{\begin{array}{ll}
\bar{l} & \text { if } R(t)>\min \left(R_{2}^{*}, \bar{R}_{1}\right) \\
(\rho / \bar{\beta})(K-R(t)) \equiv \bar{l}_{r 2}^{N *} & \text { if } R(t)=\min \left(R_{2}^{*}, \bar{R}_{1}\right) \\
0 & \text { if } R(t)<\min \left(R_{2}^{*}, \bar{R}_{1}\right)
\end{array} .\right.
\end{gathered}
$$

Here, $R_{i}^{*}$ is defined as country $i$ 's privately optimal steady state resource stock,

$$
\bar{R}_{i}^{*}=\frac{K}{4}-\frac{\delta}{4 \rho}+\frac{\alpha_{i} P_{a}}{4 \bar{\beta} P_{r}}+\sqrt{\left(\frac{K}{4}-\frac{\delta}{4 \rho}+\frac{\alpha_{i} P_{a}}{4 \bar{\beta} P_{r}}\right)^{2}+\frac{\alpha_{i} P_{a} \delta}{2 \bar{\beta} P_{r} \rho}}
$$

and $\bar{R}_{i}$ is the resource stock at which country $i$ is indifferent between allocating another unit of labor to resource harvesting or to agriculture - given that it is tied in a non- 
cooperative game with country $j$ :

$$
\bar{R}_{i}=\frac{\alpha_{i} P_{a}}{\bar{\beta} P_{r}} .
$$

In other words, $\bar{R}_{i}$ is the level of the resource stock where country $i$ 's marginal benefits of labor allocated to agriculture $\left(\alpha_{i} P_{a}\right)$ are equal to the instantaneous (or gross-) marginal benefits of resource harvesting ( $P_{r} \bar{\beta} R$, that is ignoring the user cost of harvesting).

To investigate whether contracts can be designed that are Pareto-improving compared to the non-cooperative outcome, we first identify the solution which maximizes joint profits.

Proposition 2 The program that maximizes aggregate payoffs consists of both countries adopting the best technology $\bar{\beta}$, and allocating labor as follows:

$$
\begin{gathered}
l_{r 1}^{S *}(t)=\left\{\begin{array}{lll}
\bar{l} & \text { if } R(t)>\hat{R} \\
0 & \text { if } R(t) \leq \hat{R}
\end{array},\right. \\
l_{r 2}^{S *}(t)=\left\{\begin{array}{ll}
\bar{l} \\
(\rho / \bar{\beta})\left(K-\bar{R}_{2}^{*}\right) \equiv l_{r 2}^{S *} & \text { if } \quad R(t)>R_{2}^{*} \\
0 & \text { if } R(t)<R_{2}^{*}
\end{array},\right.
\end{gathered}
$$

where $\hat{R}\left(\hat{R}>\bar{R}_{1}\right)$ is defined as the stock level at which country 1's marginal benefits of agriculture equal the net marginal benefits of resource harvesting. ${ }^{7}$

Comparing Propositions 1 and 2, both the Nash equilibrium feedback solution and the socially optimal harvesting program imply each country selecting the best technology, $\bar{\beta}$. Also, the allocation of labor over agriculture and harvesting is identical with and without cooperation in the early periods, but not in the later periods. ${ }^{8}$ Contracting with respect to the allocation of labor is typically difficult because of imperfect observability, and therefore we focus on the case in which countries can contract with respect to the harvesting technologies used. From (8) and (9) we know the following:

\footnotetext{
${ }^{7}$ Given (i) $\phi_{1}=\phi_{2}=1$ and (ii) $\beta_{1}=\beta_{2}=\bar{\beta}$, the current-value Hamiltonian of the intertemporal harvesting decision reads as $H=P_{a} \alpha_{1}\left[\bar{l}-l_{r 1}\right]+P_{r} \bar{\beta} R l_{r 1}+P_{a} \alpha_{2}\left[\bar{l}-l_{r 2}\right]+P_{r} \bar{\beta} R l_{r 2}+$ $\lambda\left[\rho R(K-R)-\bar{\beta} R\left(l_{r 1}+l_{r 2}\right)\right]$, where $\lambda$ is the shadow price of the resource stock. Then, $\hat{R}$ is implicitly defined by $\partial H / \partial l_{r 1}=0$, that is by $P_{a} \alpha_{1}=\left(P_{r}-\lambda\right) \bar{\beta} R$.

${ }^{8}$ Note that we impose the assumption about the initial abundance of the resource (given $I$ ) to rule out situations where there is no conflict of interests. One example of such a case would be the one in which both $R_{0}$ and $R_{2}^{*}$ are strictly below $\bar{R}_{1}$. Here, country 1 never undertakes any harvesting and country 2 either harvests (if $R_{2}^{*} \leq R_{0}<\bar{R}_{1}$ ) or does not harvest (if $R_{0}<R_{2}^{*}<\bar{R}_{1}$ ), but the resource always ends up in the same steady state, $R_{2}^{*}$. This would actually be socially optimal; private and social objectives coincide. To rule out such cases, we assume that the resource is sufficiently large initially. A sufficient condition is that $R_{0}>\hat{R}$, so that $R(t)<R_{0}$ for all $t>0$.
} 
Proposition 3 The contract that maximizes aggregate payoffs is given by:

$$
\begin{gathered}
\beta_{1}=\left\{\begin{array}{lll}
\bar{\beta} & \text { if } \quad R(t)>\hat{R} \\
0 & \text { if } \quad R(t) \leqslant \hat{R}
\end{array},\right. \\
\beta_{2}=\bar{\beta} \text { for all } 0 \leqslant R(t) .
\end{gathered}
$$

In words, country 2 should always harvest using technology $\bar{\beta}$, whereas country 1 should discard it when the resource stock is depleted down to $\hat{R}$. This contract is obviously both incentive-compatible and payoff-enhancing for country 2, but it is not for country 1. Indeed, if $\bar{R}_{1} \geqslant R_{2}^{*}$, country 2's best response function as described by Clark (see Proposition 1 above) coincides with the way in which country 2 should employ its labor in order to maximize aggregate payoffs. And if $\bar{R}_{1}<R_{2}^{*}$, country 2 can credibly commit to continue allocating $\bar{l}$ to resource harvesting in case country 1 reneges on the contract. ${ }^{9}$ But country 1 is not willing to sign this contract. To maximize aggregate payoffs, it should cease harvesting at a level of the resource stock $(\hat{R})$ where the instantaneous (or gross-) marginal benefits of harvesting exceed its marginal benefits of agriculture (as $\hat{R}>\bar{R}_{1}$ ). Hence, absent side payments, country 1's discounted payoff falls if it abides with the contract that maximizes joint payoffs.

Let us therefore consider whether country 2 can induce country 1 to sign a Paretoimproving contract. Given that both countries select $\bar{\beta}$ in the Nash equilibrium, we can state that aggregate payoffs increase if $\beta_{1}=\beta_{2}=\bar{\beta}-\varepsilon(\varepsilon>0)$, substituting natural resource productivity (larger $R$ ) for technical productivity (higher $\beta$ ). But contracts specifying the adoption of equally inefficient technologies by the two countries involved are not necessarily Pareto-improving. For country 1, the use of an inefficient technology implies lower harvesting productivity which is not likely to be compensated by the productivity increase associated with higher resource stocks at every point in time along the depletion path. Country 2, on the other hand, benefits from larger resource stocks not only during the transition phase, but also in the long run. Therefore, perhaps surprisingly, if side payments are not feasible, the only way in which the low opportunity cost country can induce the high opportunity cost country to sign a Pareto-improving contract is by selecting an even more inefficient technology than does the high opportunity cost country.

\footnotetext{
${ }^{9}$ Hence if country 2 uses a trigger strategy it is incentive-compatible and credible; cf. Hämäläinen et al. (1984) or Laukkanen (2003).
} 
Let us use $\left(\tilde{\beta}_{1}, \tilde{\beta}_{2}\right)$ to denote sets of technologies specified in Pareto-improving contracts. Absent side payments, country 1 is only willing to sign the contract if $\tilde{\beta}_{2}<\tilde{\beta}_{1}$. By limiting its own harvesting potential, country 2 allows country 1 to benefit from lower search costs (due to larger resource stocks) during the transition phase. But country 2 is only willing to sign the contract if $\tilde{\beta}_{1}<\bar{\beta}$; if not, aggregate payoff does not increase and country 2 would necessarily lose. Hence, Pareto-improving contracts are characterized by combinations of technologies such that $\tilde{\beta}_{2}<\tilde{\beta}_{1}<\bar{\beta}$.

Obviously, private payoffs of country 1 (2) increases if $\tilde{\beta}_{2}\left(\tilde{\beta}_{1}\right)$ falls. Hence we can determine the scope for Pareto-improving contracts by determining the combination of $\beta_{1}$ and $\beta_{2}$ that maximizes country $i$ 's payoff subject to the constraint that the other country is indifferent between signing that contract, or not. ${ }^{10}$ Let us use $\left(\tilde{\beta}_{1}^{i}, \tilde{\beta}_{2}^{i}\right), i=1,2$, to denote the sets of technologies chosen by an own-payoff maximizing country $i$ when it has the right to propose a contract. That means that $\left(\tilde{\beta}_{1}^{i}, \tilde{\beta}_{2}^{i}\right)$ is the solution of

$$
\begin{aligned}
& \max _{\beta_{1}, \beta_{2}} \prod_{i}\left(\beta_{1}, \beta_{2}\right) \text { s.t. } \\
& \Pi_{j}\left(\beta_{1}, \beta_{2}\right)=\Pi_{j}^{N a s h} .
\end{aligned}
$$

In figure 1 , we depict the combinations of $\tilde{\beta}_{1}^{i}$ and $\tilde{\beta}_{2}^{i}(i=1,2)$ as a function of heterogeneity $\left(\alpha_{1}-\alpha_{2}\right)$. We find that independent of which country can draft the proposed contract $(i=1$ or 2 ), the Pareto-improving technology level of the high opportunity cost country (country 1), $\tilde{\beta}_{1}^{i}$, is close to the maximum technology level for both low and high levels of heterogeneity, and is lowest for intermediate levels of heterogeneity. The intuition behind these results is as follows.

For low levels of heterogeneity, the two countries are too similar for country 2 to specify a contract with $\beta_{2}$ much smaller than $\beta_{1}$; its own payoff would fall. Because $\tilde{\beta}_{2}$ cannot be much lower than $\tilde{\beta}_{1}$, country 2 is not able to provide much compensation along the depletion path to induce country 1 to select a sufficiently inefficient technology. Hence,

\footnotetext{
${ }^{10}$ Country 1's commitment to using $\tilde{\beta}_{1}<\bar{\beta}$ is not time-consistent unless the discounted flow of benefits of switching from $\tilde{\beta}_{1}$ to $\bar{\beta}$ fall short of the investment costs $(I)$ associated with this switch -taking into account that country 2 can credibly commit to its trigger strategy. We assume that this is the case as designing a time-consistent contract complicates the analysis without adding additional insights. For a proper analysis of the importance of switching costs, see Nostbakken (2006). An alternative solution to the potential time-inconsistency problem would be to assume that countries can adopt a harvesting technology just once.
} 


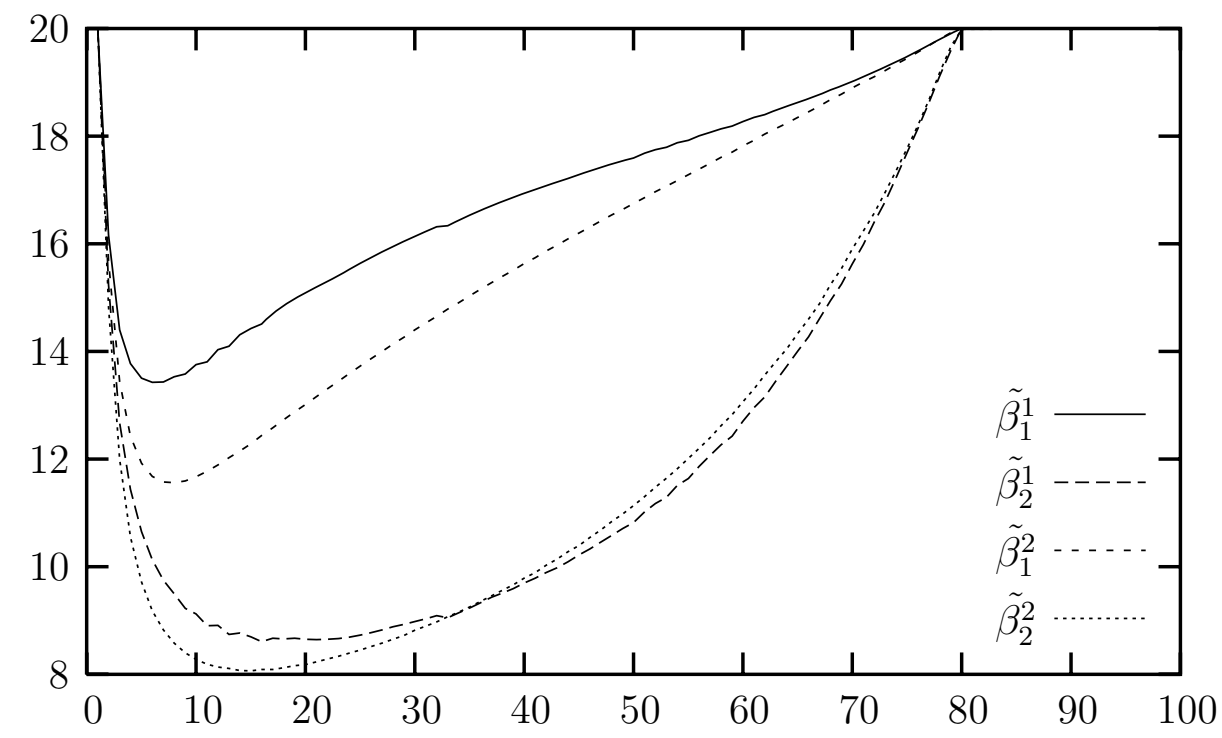

Figure 1: Combinations of technologies $\left(\tilde{\beta}_{1}^{i}, \tilde{\beta}_{2}^{i}\right)$ that maximize country $i$ 's payoff such that the other country's payoff does not fall, as a function of heterogeneity $\left(\alpha_{1}-\alpha_{2}\right)$. Parameter values: $\alpha_{2}=5, \bar{\beta}=20, \delta=0.05, K=100, \rho=0.03, R_{0}=100, P_{a}=100$, $P_{r}=10$, and $\bar{l}=1$.

$\tilde{\beta}_{1}$ cannot be too low. That means that, whichever country has the right to draw up the contract (country 1 or 2 ), the technologies specified in the contract are close to $\bar{\beta}$. Therefore, the net gain associated with signing the contracts are small.

For very high levels of heterogeneity, the possibilities for gains via cooperation are also limited, as the costs of non-cooperation are smaller. The higher $\alpha_{1}$, the shorter the time period in which country 1 engages in resource harvesting (as $\bar{R}_{1}$ is then larger). Obviously, if $\alpha_{1}$ is such that country 1 does not harvest at all (not even in period 1, and a sufficient condition for this is that $\alpha_{1}>\bar{\beta} P_{r} R_{0} / P_{a}$; see (7)), it does not pay for country 2 to choose an inefficient technology (i.e., $\tilde{\beta}_{2}=\bar{\beta}$ ). For slightly lower levels of $\alpha_{1}$, country 2 can gain from country 1 choosing a less than efficient technology, but only a little. Therefore, it is willing to accept only a very small difference in technological efficiency levels, and hence $\beta_{1}$ should be close to the maximum efficiency level. Again, that means that, whichever country has the right to draw up the contract (country 1 or 2), it can not gain much from that contract. ${ }^{11}$

\footnotetext{
${ }^{11}$ Note that for $\alpha_{1}-\alpha_{2}<30$, country 2 assigns itself an even more inferior technology than what would be assigned by country 1 ; that is, $\tilde{\beta}_{2}^{2}<\tilde{\beta}_{2}^{1}$. This may seem surprising, but it can be explained by noting that $\tilde{\beta}_{1}^{2}<<\tilde{\beta}_{1}^{1}$. In words, if country 2 has the right to make a proposal, it assigns country 1 a technology which is very much inferior to what that country would assign itself -if it had the right to draw up the contract. The only way country 2 can get away with this is by assigning itself an even worse technology,
} 
We can now establish the scope for Pareto-improving contracts by plotting the difference between $\tilde{\beta}_{j}^{1}$ and $\tilde{\beta}_{j}^{2}, j=1,2$; see figure 2 . Picking any technology level $\beta_{1} \in\left(\tilde{\beta}_{1}^{2}, \tilde{\beta}_{1}^{1}\right)$ or $\beta_{2} \in\left(\tilde{\beta}_{2}^{1}, \tilde{\beta}_{2}^{2}\right)$, we can find a $\beta_{2}$ or $\beta_{1}$ that increases private payoffs of both countries involved, and the range is largest for intermediate levels of heterogeneity.

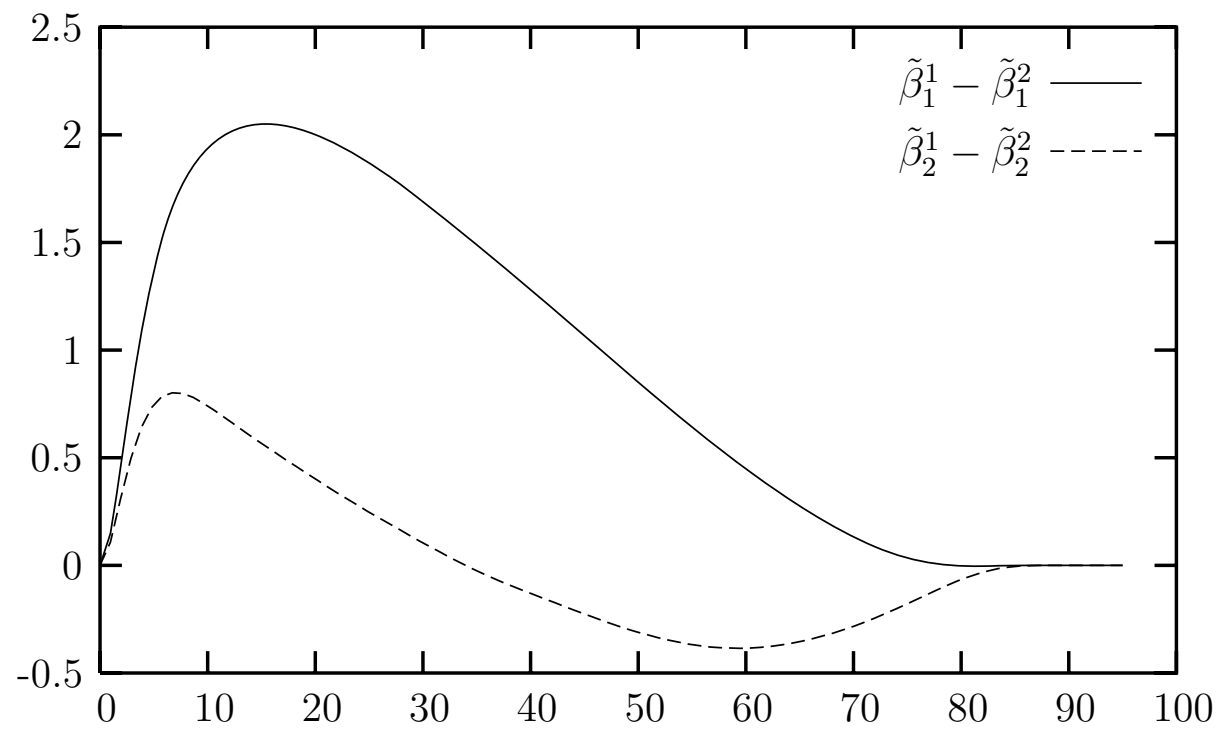

Figure 2: Ranges of technologies for countries 1 and 2 that are Pareto-improving. Parameter values: see figure 1.

\section{Conclusions}

Absent property rights, rates of exploitation are suboptimally high if a resource is shared by several countries. Cooperation can enhance aggregate payoffs but previous research suggests that, unless side payments are feasible, cooperation may be difficult to achieve when the countries involved differ with respect to important characteristics such as the (opportunity) costs of resource harvesting. The reason is that socially optimal contracts are generally not Pareto-improving if agents are heterogeneous.

In this paper, we revisit the claim that, absent side payments, achieving cooperation is more difficult the more heterogeneous the resource users are. If side payments are not feasible, the only means countries have to achieve cooperation is by establishing so that country 1 is at least as well off with the contract as without. 
Pareto-improving contracts with respect to easily observable decision variables, such as technology choice. In our two-country linear dynamic game, efficiency of resource use can be increased by contracting on a relatively inefficient technology. Harvesting productivity is a function of technological efficiency as well as of the size of the resource stock, and hence the adoption of relatively inefficient harvesting technologies can improve aggregate payoffs because they result in larger resource stocks. Each country can only induce the other country to adopt a relatively inefficient technology (that increases aggregate payoffs) if it adopts a relatively inefficient technology itself.

The scope for Pareto-improving contracts is limited, though, for both low and high levels of heterogeneity. When countries are fairly similar, the low opportunity cost country cannot afford to have a much less efficient technology than its counterpart, and hence is not able to compensate the high opportunity cost country for the adoption of a sufficiently inefficient technology. Alternatively, when countries are very dissimilar to start with, there is less necessity for the low opportunity cost country to select a technology that is much more inferior than that of its counterpart. The more dissimilar the countries involved, the smaller is the time period where the high opportunity cost country is involved in resource harvesting, and hence the smaller the scope for Pareto-improving contracts.

In summary, we find that the range of Pareto-improving technology sets is a humpshaped function of the difference in agricultural productivity. Hence we find that the scope for cooperation is largest for intermediate levels of heterogeneity. 


\section{References}

[1] Benhabib, J. and R. Radner, 1988. Joint exploitation of a productive asset: a gametheoretic approach. Economic Research Reports, 88-17, New York University, Faculty of Arts and Science, New York.

[2] Cherry, T.L., S. Kroll and J.F. Shogren, 2005. The impact of endowment heterogeneity and origin on Public Good contributions: Evidence from the lab. Journal of Economic Behavior and Organization, 57(3): 357-365.

[3] Clark, C.W., 1980. Restricted access to common-property fishery resources: A gametheoretic analysis. In: P. Lui (ed.), Dynamic optimization and mathematical economics, New York, Plenum Press: 117-132.

[4] Crabbé, Ph. and N. Van Long, 1993. Entry deterrence and overexploitation of the fishery. Journal of Economic Dynamics and Control, 17: 679-704.

[5] Gardner, R., A. Herr, E. Ostrom and J.A. Walker, 2000. The power and limitations of proportional cutbacks in common-pool resources. Journal of Development Economics, 62: 515-533.

[6] Gaspart, F. and E. Seki, 2003. Cooperation, status seeking and competitive behaviour: Theory and evidence. Journal of Economic Behavior and Organization, 51(1): 51-77.

[7] Hämäläinen, R.P., V. Kaitala and A. Haurie, 1984. Bargaining on whales: A differential game model with Pareto optimal equilibria. Operations Research Letters, 3(1): $5-11$.

[8] Hannesson, R., 1997. Fishing as a supergame. Journal of Environmental Economics and Management, 32(3): 309-322.

[9] Houba, H., K. Sneek and F. Várdy, 2000. Can negotiations prevent fish wars? Journal of Economic Dynamics and Control, 24: 1265-1280.

[10] Johnson, R.N. and G.D. Libecap, 1982. Contracting problems and regulation: The case of the fishery. American Economic Review, 72(5): 1005-1022.

[11] Laukkanen, M., 2003. Cooperative and non-cooperative harvesting in a stochastic sequential fishery. Journal of Environmental Economics and Management, 45: 454473. 
[12] Ledyard, J., 1995. Public goods: A survey of experimental research. In: Kagel, J.H. and A.E. Roth (eds.), Handbook of experimental economics, Princeton (NJ): Princeton University Press.

[13] Levhari, D. and L.J. Mirman, 1980. The great fish war: An example using a dynamic Cournot-Nash solution. Bell Journal of Economics, 11(1): 322-334.

[14] Munro, G.R., 1979. The optimal management of transboundary renewable resources. Canadian Journal of Economics, 12(3): 355-376.

[15] Nostbakken, L., 2006. Regime switching in a fishery with stochastic stock and price. Journal of Environmental Economics and Management, 51(2): 231-241.

[16] Varughese, G. and E. Ostrom, 2001. The contested role of heterogeneity in collective action: Some evidence from community forestry in Nepal. World Development, 29(5): $747-765$. 